\title{
Time-related changes in quality of life in persons with lower limb amputation or spinal cord injury: protocol for a systematic review
}

Matthew Young, Carly McKay, Sean Williams, Peter Rouse and James L. J. Bilzon * (D)

\begin{abstract}
Background: Experiencing a lower limb amputation (LLA) or spinal cord injury (SCI) is a life-changing event, affecting physical and systemic function as well as having psychological and social impacts. However, the severity of the physical impairment and/or motor disability demonstrates a poor relationship with patient-reported quality of life, suggesting that other factors determine such outcomes. As such, holistic health-related quality of life (QoL) assessment is an important tool to monitor long-term outcomes. While there are some studies that have assessed the influence of variables such as age at time of injury occurrence and time since injury on changes in QoL, there are no systematic reviews which synthesise this evidence.
\end{abstract}

Methods/design: All follow-up study designs will be included, where data from multiple time points are presented. Searches will target both SCI and LLA populations where a validated measure of QoL has been used: Medical Outcome Study Short-Form 36/12 or the World Health Organization Quality of Life instruments 100 and BREF. Studies must include adult participants ( $\geq 18$ years at time of injury) and detail time since injury event and patient age.

The primary objective is to establish the effects of participant age and time since injury on QoL scores. Secondary objectives include determining between-group effects (i.e. LLA vs. SCI).

We will search PubMed, Embase and Web of Science databases, supplemented by hand-searching references within existing review articles and experimental studies. Reviewer pairs will conduct screening and quality assessment of included papers.

Results will be stratified by impairment, QoL tool, age/time since injury and additional variables such as sex, race, comorbidity or disease aetiology, as appropriate. If sufficient high-quality data exist, a meta-analysis will be conducted.

Discussion: The results of this systematic review will summarise evidence of how QoL changes across the life course, relative to both patient age and time since injury, for both LLA and SCI populations. By enabling a direct comparison of different chronic conditions, disability-specific differences in QoL changes over the life course can be identified.

\section{Systematic review registration: PROSPERO CRD42018096633.}

Keywords: Systematic review, Lower limb amputation, Spinal cord injury, Quality of life, SF-36, WHOQOL

\footnotetext{
* Correspondence: J.Bilzon@bath.ac.uk

Department for Health, University of Bath, Bath BA2 7AY, UK

(c) The Author(s). 2019 Open Access This article is distributed under the terms of the Creative Commons Attribution 4.0 International License (http://creativecommons.org/licenses/by/4.0/), which permits unrestricted use, distribution, and reproduction in any medium, provided you give appropriate credit to the original author(s) and the source, provide a link to the Creative Commons license, and indicate if changes were made. The Creative Commons Public Domain Dedication waiver (http://creativecommons.org/publicdomain/zero/1.0/) applies to the data made available in this article, unless otherwise stated.
} 


\section{Background}

Sustaining a lower limb amputation (LLA) or spinal cord injury (SCI) is a significant event, with permanent implications for the individual's future life. The outcomes of both LLA and SCI are highly individualised and heterogeneous, in part due to variability in the level of injury/ amputation and, at least for SCI, the degree of injury completeness. The reasons for injury occurrence can also be important, with many LLA cases being related to significant existing chronic disease and related comorbidities. However, both conditions present a series of shared outcomes that have a significant impact on aspects of quality of life (QoL) [1]. For example, mobility restriction and differences in appearance lead to shared challenges around social engagement, perceived isolation and dependency, which can limit community participation [2-7] and increase risk of depression [8-11]. Similarly, a general loss of skeletal muscle mass and restriction of physical activity contribute to longterm health consequences associated with early ageing $[12,13]$ such as increased risk of cardiovascular and metabolic diseases [14-16].

Notwithstanding, several studies have demonstrated that for individuals with a chronic motor disability the level of physical impairment does not directly correlate with patient-reported quality of life [17-20]. QoL scales consider the resultant limitations and consequences of a disability and assess how these change over time, even when the underlying injury remains. As such, QoL measures are increasingly being recognised as an important tool for monitoring long-term outcomes following rehabilitation [21-24]. Used in combination with assessment of functional performance, they assist in the recording of changing perceptions and patient adjustment, as well as their acceptance of life post-injury $[25,26]$.

Researchers in both LLA and SCI communities acknowledge the value of QoL measures as longitudinal assessment tools [17, 27-31]. They provide a quantitative mechanism for capturing changes in post-injury health and broad level treatment outcomes, both for an individual and for a disability group, relative to population normative data. However, there is a lack of homogenous outcome data for both communities and a lack of consensus around QoL scale selection.

In part, this is due to the multifaceted nature of QoL as a construct. There are varying definitions and tools available, built around both conceptual understandings of what constitutes a person's quality of life and design considerations specifying what facets a tool is designed to assess and for which populations. One widely utilised distinction is that between 'objective' and 'subjective' assessment measures, previously described by Dijkers and Fuhrer [25, 26]. Several LLA and SCI reviews have followed this construct and divided existing QoL measures under these headings [27-29, 32]. Within this distinction, objective measures consider external definitions of QoL (i.e. those that are societally or culturally defined), whereas subjective measures focus on an individual's perceptual assessment of their life relative to their expectations.

These distinctions are particularly important to consider when QoL tools have been deployed longitudinally, or when trying to capture within-population differences in response to rehabilitation or treatment. Both components of QoL should be reflected when attempting to create more personalised rehabilitation or recovery pathways for specific patient sub-groups. For example, there are ongoing shifts in the population demographics for both SCI and LLA [33-35]. For SCI, age at onset is subject to considerable variation globally, with increasingly ageing populations in more economically developed countries (MEDC) highlighted as a potential future public health challenge [36]. Similarly for LLA, there is significant variation between countries for age at onset, aetiology and incidence [37, 38]. This variation encompasses a complex landscape, with regional public health provision intersecting with clinical advances.

Regardless, within both conditions, mean and upper age at onset and potentially life expectancy is increasing for both populations, in particular within MEDCs [34, 35, 39-41]. Furthermore, it has been noted that a bimodal distribution may be forming for both conditions, $[35,42]$ with traumatic injuries relating to misadventure or conflict continuing to occur at younger ages, while the proportion whose injury results from age- or lifestyle-related factors, such as vascular disease for LLA or frailty-related falls for SCI, increases.

This potentially growing divide in age at time of injury occurrence raises questions around identifying rehabilitation or treatment requirements for different age groups $[43,44]$. It also has implications when considering functional and QoL outcomes across the life course and when selecting QoL instruments [45-47].

Previous research has been undertaken comparing SCI and LLA population QoL outcomes to population norms and healthy controls [27], but no cross-population comparisons have been reported. This leads to important questions regarding how the comparative success of long-term rehabilitation and recovery pathways can be evaluated and optimised to sustain QoL. By directly comparing the QoL scores at an individual health domain level (e.g. Physical Health, Psychological, Social Relationship and Environment for WHOQOL-BREF), we may gain insight into the condition-specific challenges of living with these disabilities.

There is a significant challenge in assessing long-term quality of life changes relative to age, due in part to a 
lack of longitudinal data in both SCI and LLA populations, particularly for those who suffered an injury in later life [19, 34, 48, 49]. As population demographics change and post-operative life expectancy rates can be expected to improve, the detail of variation in QoL relative to time since injury and age at onset holds increasing importance $[33,45]$. There is currently a lack of consensus around the relationship between QoL with age at time of injury and time since injury, both for persons with SCI [48] and those with LLA [50, 51].

This review intends to provide a synthesis of these previously unassessed variables, alongside aetiology characteristics, to address this issue. This is required as the emergence of increasingly divided points of disability incidence may necessitate changes in care provision or categorisation.

\section{Aim}

The primary purpose of this systematic review is to evaluate current evidence to determine the independent and combined effects of age at time of injury and time since injury on health-related quality of life in persons with spinal cord injury or lower limb amputation. Where there are a sufficient number and quality of articles, analyses will be performed to determine differences in the effects of these variables, between groups and over time. The secondary purpose of the review is to determine the potential effects of other variables (e.g. sex, ethnicity, injury type impairment/function score).

\section{Methods/design}

This protocol follows the principles of The Cochrane Handbook for Systematic Reviews, and the final report will conform to the Preferred Reporting Items for Systematic Reviews and Meta-Analyses [52, 53]. The Preferred Reporting Items for Systematic Reviews and Meta-Analyses (PRISMA-P) process will be followed, as presented in Additional file 1.

This protocol was registered with the PROSPERO International Prospective Register of Systematic Reviews database (registration number CRD42018096633).

\section{QoL tool selection}

When deciding which quality of life (QoL) measures to include in this review, we required scales which (i) had been assessed for validity and reliability in both SCI and LLA populations, (ii) were in common use and, if possible, (iii) reflected both aspects of subjective and objective QoL assessment [25].

Several reviews have summarised both the utilisation and validity of QoL tools for SCI and LLA populations $[27-31,48,54,55]$. These indicate that the WHOQOLBREF [56] and Medical Outcomes SF-36 [57] are in common use and considered amongst the best available generic tools for both groups. The SF-36 is an objective tool, and the WHOQOL-BREF is considered subjective, although it has objective elements [27, 32, 54].

The SF-36 has been reported as one of the most widely evaluated generic health measures [58], and this is consistent with utilisation in LLA and SCI populations $[48,55,59]$. The SF-12 is also used in both populations, retains the same sub-domains as the SF-36 and has been shown to have good agreement with the longer form [60]. While the WHOQOL-BREF has been used less frequently, particularly in studies of persons with LLA, it has been extensively assessed [24, 32, 61-63] and is sometimes preferred because of its mixed subjective/objective features [29].

These scales are both subdivided into domains allowing sub-component analysis. Furthermore, the convergence and agreement between the two scales has been previously assessed and found acceptable in SCI and 27 other health conditions, although LLA has not been investigated as an independent health condition [32, 61]. For completeness, although it is used less frequently, data derived from the full WHOQOL-100 [64] survey will also be included.

\section{Eligibility criteria for consideration of inclusion}

We will adopt an inclusive approach where all follow-up study designs, where data from multiple time points are presented, with any publication date, written in the English Language, will be eligible if they present data on adults $(\geq$ 18 years at time of injury) with either SCI or LLA.

Studies will be required to utilise either (or combinations of) the Medical Outcome Study Short-Form 36/12 or the World Health Organization Quality of Life instruments 100 and BREF to assess patient health-related quality of life and provide sufficient detail to extract domain level scores. That is, the WHOQOL instruments define 4 domains (i.e. Physical Health, Psychological, Social relationship and Environment), while the Medical Outcome Study details two domains, Physical and Mental, which have four subsections each.

Additionally, studies must detail the sample's age and/ or the time since injury event/onset and present data from at least two follow-up time points. Furthermore, only LLA studies examining above ankle amputation will be included.

\section{Information sources and literature search strategy}

The literature search strategy will be based around the digital libraries of PubMed, Embase and Web of Science Core Collection. This will be supplemented through a hand search of references within existing review articles and selected experimental studies.

Specific search strategies will utilise both medical subject headings $(\mathrm{MeSH})$ or database-specific equivalents 
and free text terms to maximise study identification. These are detailed in Additional file 2.

\section{Study selection process}

The citations of all records retrieved with be downloaded to Mendeley Desktop [65] (Version 1.17.13) for record keeping and duplicate removal. The title and abstract of entries will then be transferred to a Microsoft Excel [66] spreadsheet for appraisal and selection for full paper review. To minimise the risk of investigator bias, a team of four independent reviewers will be divided into two reviewer pairs to conduct all levels of screening and quality assessment. Use of multiple reviewer pairs will allow the rotation of citation assessment at abstract and full paper stages to further reduce reviewer bias. Discrepancies will be resolved by within-pair discussion and then by inclusion of an additional independent reviewer until consensus is reached. Cohen's kappa statistic [67] will be calculated to determine the inter-rater agreement for study inclusion.

\section{Data extraction}

Data to be extracted will include basic descriptive characteristics of the study (e.g. study design, year of publication, sample size, country of study); baseline participant characteristics both for injury type (LLA/SCI) and level of injury (i.e. above/below knee amputation; American Spinal Injury Association (ASIA) Impairment Scale and level of injury), aetiology of injury (i.e. trauma, vascular, cancer, etc.), personal characteristics (i.e. age, sex, comorbidity, time since injury, social status) and outcome results (i.e. quality of life scale used and scores across domains/sub-domains). The data extraction form will be pilot tested by two reviewers on 10 papers [68] and modified to reflect the level and specificity of data available.

\section{Data synthesis}

The results of the systematic review will be summarised descriptively and quantitatively, assuming the appropriate data are available. Data will be considered across the two QoL scales, with results grouped by scale sub-domains, injury type and sub-population. We will conduct separate sub-group analyses across these strata and provide composite information where possible. Normative population data, where available, will also be referenced for comparative analysis. As age and time since injury are key variables, where these data are not available, additional data will be requested from corresponding authors.

Where sufficient data for meta-analysis are available, a mixed effects meta-regression model using the 'metafor' package in R (version 3.2.4, R Foundation for Statistical Computing, Vienna, Austria) will be used [69]. The modifying effects of age and time since injury on QoL outcomes will be evaluated as the change associated with a two standard deviation (SD) change in the predictor (i.e. a typically low vs. a typically high value) [70]. The random effects in the model will be a between-study SD, representing the typical difference in the true value of the effect in different study settings, plus a within-study random effect to account for within-study repeated measurements.

\section{Quality assessment}

The risk of bias within individual studies will be assessed using the Cochrane Risk of Bias Tool [52] for randomised trials, and the NIH Quality Assessment Tool for Observational Cohort and Cross-Sectional Studies [71]. Regardless of quality score, papers will be included in the final review and analyses, but summarised descriptively according to risk of bias. Corresponding authors will be contacted if insufficient details exist to confidently assess the risk of bias in individual studies.

\section{Discussion}

This systematic review and meta-analysis is designed to assess the independent and combined effects of age at time of injury and elapsed time since injury on quality of life in persons with chronic SCI and LLA.

By taking a cross-population perspective, this review will highlight potential discrepancies in QoL outcome for each group across the various sub-domains of the two QoL scales. This may also allow further comparative analysis between the SF-36 and WHOQOL BREF scales for use in disabled populations. Given the heterogeneity of aetiology for both conditions, a comparative view of rehabilitative outcomes is necessary to identify any global failings or successes of rehabilitative practice for the different conditions.

\section{Additional files}

Additional file 1: PRISMA-P 2015 checklist. (DOCX $38 \mathrm{~kb}$ )

Additional file 2: Search terms. (DOCX $76 \mathrm{~kb}$ )

\section{Abbreviations}

ASIA: American Spinal Injury Association; LLA: Lower limb amputation; MEDC: More economically developed country; MESH: Medical subject headings; PRISMA-P: Preferred Reporting Items for Systematic Reviews and Meta-Analysis Protocols; QoL: Quality of Life; SCl: Spinal cord injury;

SD: Standard deviation; SF-12: Medical Outcomes Study 12-Item Short-Form Health Survey; SF-36: Medical Outcomes Study 36-Item Short-Form Health Survey; WHOQOL-100: World Health Organization Quality of Life Assessment; WHOQOL-BREF: World Health Organization Quality of Life Assessment-BREF

\section{Acknowledgements \\ Not applicable.}

Authors' contributions

$M Y, J B, C M$ and PR contributed to the conception and design of the review. MY drafted the initial version of the protocol and derived the search strategy. SW and MY prepared the meta-analysis plan. MY wrote the first 
draft. CM, SW, PR and JB contributed to the review of the manuscript and approved the final version. All authors read and approved the final manuscript.

\section{Funding}

MY's post is supported by CAMERA, the RCUK Centre for the Analysis of Motion, Entertainment Research and Applications, EP/M023281/1.

\section{Availability of data and materials}

The datasets generated and/or analysed during the current study are available from the corresponding author on reasonable request.

\section{Ethics approval and consent to participate}

Not applicable.

\section{Consent for publication}

Not applicable.

\section{Competing interests}

The authors declare that they have no competing interests.

Received: 18 June 2018 Accepted: 22 July 2019

Published online: 02 August 2019

\section{References}

1. Cavigelli A, Fischer R, Dietz V. Socio-economic outcome of paraplegia compared to lower limb amputation. Spinal Cord. 2002;40(4):174-7. https:// doi.org/10.1038/sj.sc.3101270.

2. Pollard C, Kennedy P. A longitudinal analysis of emotional impact, coping strategies and post-traumatic psychological growth following spinal cord injury: a 10-year review. Br J Health Psychol. 2007;12(3):347-62. https://doi. org/10.1348/135910707X197046.

3. Charlifue S, Gerhart K. Community integration in spinal cord injury of long duration. NeuroRehabilitation. 2004;19(2):91-101 https://content.iospress. com/articles/neurorehabilitation/nre00219. Accessed 31 Jan 2018.

4. Pell JP, Donnan PT, Fowkes FG, Ruckley CV. Quality of life following lower limb amputation for peripheral arterial disease. Eur J Vasc Surg. 1993;7(4):448-51 http://www.ncbi.nlm.nih.gov/pubmed/8359304. Accessed 31 Jan 2018.

5. Dunne S, Coffey L, Gallagher P, Desmond D, Ryall N. Beyond function: using assistive technologies following lower limb loss. J Rehabil Med. 2015;47(6): 561-8. https://doi.org/10.2340/16501977-1962.

6. Nunes MA, de Barros N, Miranda F, Baptista-Silva JC. Common mental disorders in patients undergoing lower limb amputation: a populationbased sample. World J Surg. 2012;36(5):1011-5. https://doi.org/10.1007/ s00268-012-1493-4.

7. Horgan O, Maclachlan M. Psychosocial adjustment to lower-limb amputation : a review psychosocial adjustment to lower-limb amputation a review. Disabil Rehabil. 2004;26(14-15):837-50. https://doi.org/10.1080/ 09638280410001708869.

8. Williams R, Murray A. Prevalence of depression after spinal cord injury: a meta-analysis. Arch Phys Med Rehabil. 2015;96(1):133-40. https://doi.org/1 0.1016/j.apmr.2014.08.016.

9. Hartoonian N, Hoffman JM, Kalpakjian CZ, Taylor HB, Krause JK, Bombardier $\mathrm{CH}$. Evaluating a spinal cord injury-specific model of depression and quality of life. Arch Phys Med Rehabil. 2014;95(3):455-65. https://doi.org/10.1016/j. apmr.2013.10.029.

10. Assimakopoulos K, Giannakopoulou F, Karaivazoglou K, Iconomou G, Mantzaroglou C, Argyriou AA. Changes in psychosocial status after lower limb amputation in a patient with severe neuropathic pain because of Maffucci's syndrome. J Pain Symptom Manag. 2009;37(4):e9-e12. https://doi. org/10.1016/j.jpainsymman.2008.11.003.

11. Hoffman RD, Saltzman CL, Buckwalter JA. Outcome of lower extremity malignancy survivors treated with transfemoral amputation. Arch Phys Med Rehabil. 2002;83(2):177-82. https://doi.org/10.1053/apmr.2002.27461.

12. Smith AE, Molton IR, Jensen MP. Self-reported incidence and age of onset of chronic comorbid medical conditions in adults aging with long-term physical disability. Disabil Health J. 2016;9(3):533-8. https://doi.org/10.1016/J. DHJO.2016.02.002.
13. Groah SL, Charlifue S, Tate D, et al. Spinal cord injury and aging: challenges and recommendations for future research. Am J Phys Med Rehabil. 2012; 91(1):80-93. https://doi.org/10.1097/phm.0b013e31821f70bc.

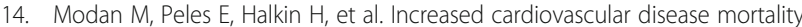
rates in traumatic lower limb amputees. Am J Cardiol. 1998;82(10):1242-7 http://www.ncbi.nlm.nih.gov/pubmed/9832102. Accessed 8 Feb 2018.

15. Garshick E, Kelley A. A prospective assessment of mortality in chronic spinal cord injury. Spinal Cord. 2005;43(June 2003):408-16. https://doi. org/10.1038/sj.sc.3101729.A

16. Myers J, Lee M, Kiratli J. Cardiovascular disease in spinal cord injury: an overview of prevalence, risk, evaluation, and management. Am J Phys Med Rehabil. 2007;86(2):142-52. https://doi.org/10.1097/PHM.0b013e31802f0247.

17. Penn-Barwell JG. Outcomes in lower limb amputation following trauma: a systematic review and meta-analysis. Injury. 2011;42(12):1474-9. https://doi. org/10.1016/j.injury.2011.07.005

18. Cushman A, Hassett J. Spinal cord injury: 10 and 15 years after. Paraplegia. 1992:30:690-6. https://doi.org/10.1038/sc.1992.135.

19. Rousseau M-C, Baumstarck K, Billette de Villemeur T, Auquier P. Evaluation of quality of life in individuals with severe chronic motor disability: a major challenge. Intractable Rare Dis Res. 2016;5(2):83-9. https://doi.org/10.5582/ irdr.2016.01017.

20. Fortington LV, Dijkstra PU, Bosmans JC, Post WJ, Geertzen JHB. Change in health-related quality of life in the first 18 months after lower limb amputation: a prospective, longitudinal study. J Rehabil Med. 2013;45(6): 587-94. https://doi.org/10.2340/16501977-1146.

21. Dijkers MPJM. Correlates of life satisfaction among persons with spinal cord injury. Arch Phys Med Rehabil. 1999;80(8):867-76. https://doi.org/10.1016/ S0003-9993(99)90076-X.

22. Post M, Noreau L. Quality of life after spinal cord injury. J Neurol Phys Ther. 2005;29(3):139-46. https://doi.org/10.1097/01.NPT.0000282246.08288.67.

23. Nissen SJ, Newman WP. Factors influencing reintegration to normal living after amputation. Arch Phys Med Rehabil. 1992;73(6):548-51 http://www. ncbi.nlm.nih.gov/pubmed/1622303. Accessed 9 Feb 2018.

24. Ackerley SJ, Gordon HJ, Elston AF, Crawford LM, McPherson KM. Assessment of quality of life and participation within an outpatient rehabilitation setting. Disabil Rehabil. 2009;31(11):906-13. https://doi. org/10.1080/09638280802356419.

25. Dijkers MP. Individualization in quality of life measurement: instruments and approaches. Arch Phys Med Rehabil. 2003;84:S3-S14. https://doi.org/10.1 053/APMR.2003.50241.

26. Fuhrer MJ. Subjectifying quality of life as a medical rehabilitation outcome. Disabil Rehabil. 2000;22(11):481-9. https://doi.org/10.1080/096382800413961.

27. Boakye M, Leigh BC, Skelly AC. Quality of life in persons with spinal cord injury: comparisons with other populations. J Neurosurg Spine. 2012;17(1 Suppl):29-37. https://doi.org/10.3171/2012.6.AOSPINE1252.

28. Wilson JR, Hashimoto RE, Dettori JR, Fehlings MG. Spinal cord injury and quality of life: a systematic review of outcome measures. Evid Based Spine Care J. 2011;2(1):37-44. https://doi.org/10.1055/s-0030-1267085.

29. Hill MR, Noonan VK, Sakakibara BM, Miller WC, Team SR. Quality of life instruments and definitions in individuals with spinal cord injury: a systematic review. Spinal Cord. 2010;48(6):438-50. https://doi.org/10.1 038/sc.2009.164.

30. Sinha R, Wim JA. A systematic literature review of quality of life in lower limb amputees. Disabil Rehabil. 2011;33(11):883-99. https://doi.org/10.3109/ 09638288.2010 .514646

31. Aquarone RL, Faro ACME. Scales on Quality of Life in patients with spinal cord injury: integrative review. Einstein (São Paulo). 2014;12(55 11):245-50. https://doi.org/10.1590/S1679-45082014RW2591.

32. Lin M-R, Hwang H-F, Chen C-Y, Chiu W-T. Comparisons of the brief form of the World Health Organization Quality of Life and Short Form-36 for persons with spinal cord injuries. Am J Phys Med Rehabil. 2007:86(2):104-13. https://doi.org/10.1097/01.phm.0000247780.64373.0e.

33. Furlan JC, Kattail D, Fehlings M. The impact of co-morbidities on age-related differences in mortality after acute traumatic spinal cord injury. J Neurotrauma. 2009;1367(0897-7151 (Print)):1361-7. https:/doi.org/10.1089/neu.2008-0764.

34. Fortington LV, Geertzen JHB, van Netten JJ, Postema K, Rommers GM, Dijkstra PU. Short and Long term mortality rates after a lower limb amputation. Eur J Vasc Endovasc Surg. 2013;46(1):124-31. https://doi.org/1 0.1016/j.ejvs.2013.03.024.

35. Ziegler-Graham K, MacKenzie E, Ephraim P, Travison T, Brookmeyer R. Estimating the prevalence of limb loss in the United States: 2005 to 
2050. Arch Phys Med Rehabil. 2008;89(3):422-9. https://doi.org/10.1 016/j.apmr.2007.11.005

36. Singh A, Tetreault L, Kalsi-Ryan S, Nouri A, Fehlings MG. Global prevalence and incidence of traumatic spinal cord injury. Clin Epidemiol. 2014;6:309-31. https://doi.org/10.2147/CLEP.S68889.

37. Moxey PW, Gogalniceanu P, Hinchliffe RJ, et al. Lower extremity amputations - a review of global variability in incidence. Diabet Med. 2011; 28(10):1144-53. https://doi.org/10.1111/j.1464-5491.2011.03279.x.

38. Group TGLEAS. Epidemiology of lower extremity amputation in centres in Europe, North America and East Asia. Br J Surg. 2000;87(3):328. https://doi. org/10.1046/j.1365-2168.2000.01344.x.

39. Strauss DJ, DeVivo MJ, Paculdo DR, Shavelle RM. Trends in life expectancy after spinal cord injury. Arch Phys Med Rehabil. 2006;87(8):1079-85. https:// doi.org/10.1016/j.apmr.2006.04.022.

40. Shavelle RM, Devivo MJ, Brooks JC, Strauss DJ, Paculdo DR. Improvements in long-term survival after spinal cord injury? Arch Phys Med Rehabil. 2015; 96(4):645-51. https://doi.org/10.1016/j.apmr.2014.11.003.

41. O'Connor PJ. Survival after spinal cord injury in Australia. Arch Phys Med Rehabil. 2005:86(1):37-47. https://doi.org/10.1016/j.apmr.2004.03.018.

42. Van Den Berg MEL, Castellote JM, Mahillo-Fernandez I, De Pedro-Cuesta J. Incidence of spinal cord injury worldwide: a systematic review. Neuroepidemiology. 2010;34(3):184-92. https://doi.org/10.1159/000279335

43. Game F. Choosing life or limb. Improving survival in the multi-complex diabetic foot patient. Diabetes Metab Res Rev. 2012;28(SUPPL. 1):97-100. https://doi.org/10.1002/dmrr.2244.

44. Scivoletto G, Morganti B, Ditunno P, Ditunno JF, Molinari M. Effects on age on spinal cord lesion patients' rehabilitation. Spinal Cord. 2003;41(8):457-64. https://doi.org/10.1038/sj.sc.3101489.

45. Pershouse KJ, Barker RN, Kendall MB, et al. Investigating changes in quality of life and function along the lifespan for people with spinal cord injury. Arch Phys Med Rehabil. 2012;93(3):413-9. https://doi.org/1 0.1016/j.apmr.2011.10.014

46. Post MWM, Reinhardt JD. Participation and life satisfaction in aged people with spinal cord injury: does age at onset make a difference? Top Spinal Cord Inj Rehabil. 2015;21(3):233-40. https://doi.org/10.1310/sci2103-233.

47. Leduc BE, Lepage $Y$. Health-related quality of life after spinal cord injury. Disabil Rehabil. 2002;24(4):196-202.

48. $\mathrm{Ku} \mathrm{JH}$. Health-related quality of life in patients with spinal cord injury: review of the short form 36-health questionnaire survey. Yonsei Med J. 2007:48(3):360-70. https://doi.org/10.3349/ymj.2007.48.3.360.

49. van Netten JJ, Fortington LV, Hinchliffe RJ, Hijmans JM. Early post-operative mortality after major lower limb amputation: a systematic review of population and regional based studies. Eur J Vasc Endovasc Surg. 2016; 51(2):248-57. https://doi.org/10.1016/J.EJVS.2015.10.001.

50. Amtmann D, Morgan SJ, Kim J, Hafner BJ. Health-related profiles of people with lower limb loss. Arch Phys Med Rehabil. 2015;96(8):1474-83. https:// doi.org/10.1016/j.apmr.2015.03.024.

51. Akyol Y, Tander B, Salim Goktepe A, Safaz I, Kuru O, Kenan TA. Quality of life in patients with lower limb amputation: does it affect postamputation pain, functional status, emotional status and perception of body image? J Musculoskelet Pain. 2013;2(214):334-40. https://doi.org/1 0.3109/10582452.2013.851761.

52. Higgins JPT, Green S (editors). Cochrane Handbook for Systematic Reviews of Interventions Version 5.1.0 2011. [Updated March 2011]

53. Moher D, Liberati A, Tetzlaff J, Altman DG, PRISMA Group. Preferred Reporting Items for Systematic Reviews and Meta-Analyses: The PRISMA Statement. PLoS Med. 2009;6(7):e1000097. https://doi.org/1 0.1371/journal.pmed.1000097

54. Hill M, Noonan V, Sakakibara B, Miller W, Scire T, Team R. REVIEW quality of life instruments and definitions in individuals with spinal cord injury: a systematic review. Spinal Cord. 2009;48(6):438-50. https://doi. org/10.1038/sc.2009.164

55. Hawkins AT, Henry AJ, Crandell DM, Nguyen LL. A systematic review of functional and quality of life assessment after major lower extremity amputation. Ann Vasc Surg. 2014;28(3):763-80. https://doi.org/10.1016/J AVSG.2013.07.011.

56. Development of the World Health Organization WHOQOL-BREF quality of life assessment. The WHOQOL group. Psychol Med 1998:28(3):551-558. http://www.ncbi.nlm.nih.gov/pubmed/9626712. Accessed 6 Feb 2018.
57. Ware JE, Sherbourne CD. The MOS 36-item short-form health survey (SF-36). 1. Conceptual framework and item selection. Med Care. 1992:30(6):473-83 http://www.ncbi.nlm.nih.gov/pubmed/1593914. Acceessed 6 Feb 2018.

58. Ware JE. SF-36 Health Survey Update. Spine (Phila Pa 1976). 2000;25(24): 3130-9. https://insights.ovid.com/pubmed?pmid=11124729. Accessed 6 Feb 2018.

59. Sinha R, Van Den Heuvel WJA, Arokiasamy P. Adjustments to amputation and an artificial limb in lower limb amputees. Prosthetics Orthot Int. 2014 38(2):115-21. https://doi.org/10.1177/0309364613489332.

60. Ware J, Kosinski M, Keller SD. A 12-Item Short-Form Health Survey: construction of scales and preliminary tests of reliability and validity. Med Care. 1996;34(3):220-33 http://www.ncbi.nlm.nih.gov/pubmed/8628042. Accessed 6 Feb 2018

61. Skevington SM, Mccrate FM. Expecting a good quality of life in health: assessing people with diverse diseases and conditions using the WHOQOL-BREF. Health Expect. 2012;15(1):49-62. https://doi.org/10.1111/ j.1369-7625.2010.00650.x.

62. Chapin MH, Miller SM, Ferrins JM, Chan F, Rubin SE. Psychometric validation of a subjective well-being measure for people with spinal cord injuries. Disabil Rehabil. 2004;26(19):1135-42. https://doi.org/10.1 080/09638280410001714772.

63. Jang $Y$, Hsieh $C-L$, Wang $Y-H$, Wu Y-H. A validity study of the WHOQOL-BREF assessment in persons with traumatic spinal cord injury. Arch Phys Med Rehabil. 2004:85(11):1890-5.

64. WHOQOL Group. The development of the World Health Organization Quality of Life Assessment Instrument (the WHOQOL). Qual Life Assess Int Perspect. 1994:41-57. https://doi.org/10.1007/978-3-642-79123-9_4.

65. Mendeley Ltd. Mendeley Desktop. Sort. 2011;257:1-10. https://doi.org/1 0.3163/1536-5050.98.2.021.

66. Microsoft. Microsoft Excel for Mac. 2017.

67. Cohen J. A coefficient of agreeement for nominal scales. Educ Psychol Meas. 1960;20:37-46.

68. Long L. Routine piloting in systematic reviews--a modified approach? Syst Rev. 2014;3:77. https://doi.org/10.1186/2046-4053-3-77.

69. Viechtbauer $\mathbf{W}$. Conducting meta-analyses in $\mathrm{R}$ with the metafor package. J Stat Softw. 2010;36(3):1-48. https://doi.org/10.18637/jss.v036.i03.

70. Hopkins WG, Marshall SW, Batterham AM, Hanin J. Progressive statistics for studies in sports medicine and exercise science. Med Sci Sports Exerc. 2009; 41(1):3-12. https://doi.org/10.1249/MSS.0b013e31818cb278.

71. Health $\mathrm{NI}$ of. NIH Quality Assessment Tool for Observational Cohort and Cross-sectional Studies. National Heart, Lung, and Blood Institute. https:// www.nhlbi.nih.gov/health-pro/guidelines/in-develop/cardiovascular-riskreduction/tools/cohort. Published 2014

\section{Publisher's Note}

Springer Nature remains neutral with regard to jurisdictional claims in published maps and institutional affiliations.

Ready to submit your research? Choose BMC and benefit from:

- fast, convenient online submission

- thorough peer review by experienced researchers in your field

- rapid publication on acceptance

- support for research data, including large and complex data types

- gold Open Access which fosters wider collaboration and increased citations

- maximum visibility for your research: over $100 \mathrm{M}$ website views per year

At BMC, research is always in progress.

Learn more biomedcentral.com/submissions 